\title{
Good Housekeeping Implementation for Improving Efficiency in Cassava Starch Industry (Case Study : Margoyoso District, Pati Regency)
}

\author{
Wijayanto Setyo Aji ${ }^{1, *}$, Purwanto $\mathrm{P}^{1,2}$, and Suherman $\mathrm{S}^{1,2}$ \\ ${ }^{1}$ Master Program of Environmental Science, School of Postgraduate Studies, Diponegoro University, Semarang - Indonesia \\ ${ }^{2}$ Department of Chemical Engineering, Faculty of Engineering, Diponegoro Univers ity, Semarang - Indonesia
}

\begin{abstract}
Cassava starch industry is one of the leading small-medium enterprises (SMEs) in Pati Regency. Cassava starch industry released waste that reduces the quantity of final product and potentially contamined the environment. This study was conducted to observe the feasibility of good housekeeping implementation to reduce waste and at the same time improve efficiency of production process. Good housekeeping opportunities are consideration by three aspect, technical, economy and environmental. Good housekeeping opportunities involved water conservation and waste reduction. These included reuse of water in washing process, improving workers awareness in drying section and packaging section. Implementation of these opportunities can reduce water consumption, reduce wastewater and solid waste generation also increased quantity of final product.
\end{abstract}

\section{Introduction}

Tapioca starch industries are one of the leading Small and Medium Enterprises (SMEs) that played important role of Pati Regency economy. Tapioca starch industries in Pati can produced 146.491 ton tapioca starch per year and have production value approximately 200 million dollars per year [1]. Tapioca starch is produced from cassava root and used for food industries especially cracker industries. Currently, the number of tapioca starch industry in Pati Regency were 600 units in 2014 and increasing every years. Tapioca starch manufacture spread in five districts with the highest number of manufactures located in Margoyoso district. Generally, production process of tapioca starch running for nine months, depending on the harvest season and raw material availability.

Production process of tapioca starch consist of 7 major step, cutting rods cassava, washing and peeling cassava, rasping cassava, pulp extraction, starch pulp separation, drying, milling and packaging.

Currently, tapioca starch industry are often causes environmental problems because of the waste, either from inefficient production process or from by-product of production process. According to the study of Prayitno (2009), the generation of wastewater at the tapioca starch industries in Margoyoso was $7.11 \mathrm{~m}^{3}$ [2]. Chavalparit \& Ongwandee reported the approximate generations of wastewater and solid waste are $12 \mathrm{~m}^{3}$ and $3 \mathrm{~kg}$ per ton of tapioca starch [3]. In addition, on 2016 farmers fish-ponds in Langgenharjo wasn't completed harvest because of water ponds contaminated with waste from tapioca starch activities. Therefore, it needs action to reduce the negative impact of tapioca starch to environment.

An approach which can be applied to improve efficiency and reduce waste generation is cleaner production. Cleaner production is the continuous application of an integrated, preventive environment strategy towards processes, products, and services in order to increase overall efficiency and reduce damage and risks for humans and the environment [4]. Cleaner production as a proven effective and economically viable approach for waste prevention and management for SMEs in developing countries [5].

One of the tools that used in the application of cleaner production is good housekeeping (GHK). Good housekeeping associated with changes the procedural action, administrative and institutional with purpose to preventing the generation of waste, enhance organizational and workplace safety. Good housekeeping activities such as, human resources development, prevention of loss material and resources, repair procedures for handling and controlling the supply of materials or resources, improvement of production schedules and separation of waste by type.

The implementation of good housekeeping is relatively easy and can be accomplished with low cost even no investment cost [6]. As we know, the reasons why SMEs do not engage in environmentally friendly practices or make environmental improvements are their perceptions that these represent a cost and most of them are skeptical about potential cost savings [7]. Thus, this tool are particularly convenient for Small and Medium Enterprises especially for tapioka starch industry. Based on study of Kumalasari et al, stated that GHK action on 
small scale cracker industry by increasing the awareness of employees at production process and clean impurities on production tools before washing can reduce water consumption to $22.04 \%$ [8]. Changes in standard operational procedure for process of shipping wine it has been proven to reduce environmental impact to 13 percent [9].

The objective of this paper is to develop good housekeeping opportunities for tapioca starch industry in order to improve production efficiency and reduce waste generation.

\section{Method}

This study was located on UD Sinar Cerah in Margoyoso District. In this study, a systematic methodology to improve efficiency and reduce waste generation consists of five step as follows :

1. Observed of production process and collecting information related consumption of resources and wastes generation.

2. Detailed evaluation and measurements of consumption of resources and wastes generation. During evaluation, production process were analyzed in detailed and translated into a flowsheet diagram that showing input and output of resources nad waste generation at each step of production process. This flowsheet shows the type of resources consumed, the type of waste generation and the sources of loss in the production process. These results served as basic to develop good housekeeping opportunities.

3. Proposing good housekeeping opportunities based on evaluation and measurement results.

4. Evaluation the feasibility of good housekeeping opportunities in term of technical, economical benefits and environmental impacts. Feasibility studies were performed to prioritize the most feasible and beneficial options. However, since small and medium scale enterprises have very limited financial resources and capabilities, the alternatives good housekeeping must therefore be economically reasonable and affordable [10].

5. Recommendation of alternatives good housekeeping opportunities to improve efficiency and reduce waste generation.

\section{Results and Discussion}

\subsection{Company Profile}

Production capacity of UD Sinar Cerah per day approximately 10 ton of tapioca starch and using cassava roots about 50 ton. The numbers of workers are varies because of their status only daily labor dan hired labor, but the numbers on average is 40 workers per day. Production process run daily from 07.00 to 15.00 with break time on 11.30 until 12.30. Sales area for UD Sinar Cerah is cover up Bandung and Surabaya areas to provided cracker industry.

\subsection{Production Process}

Production process of tapioca starch at the study location shown in Fig. 1. The flowsheet diagram are based on 50 ton of cassava as raw material.

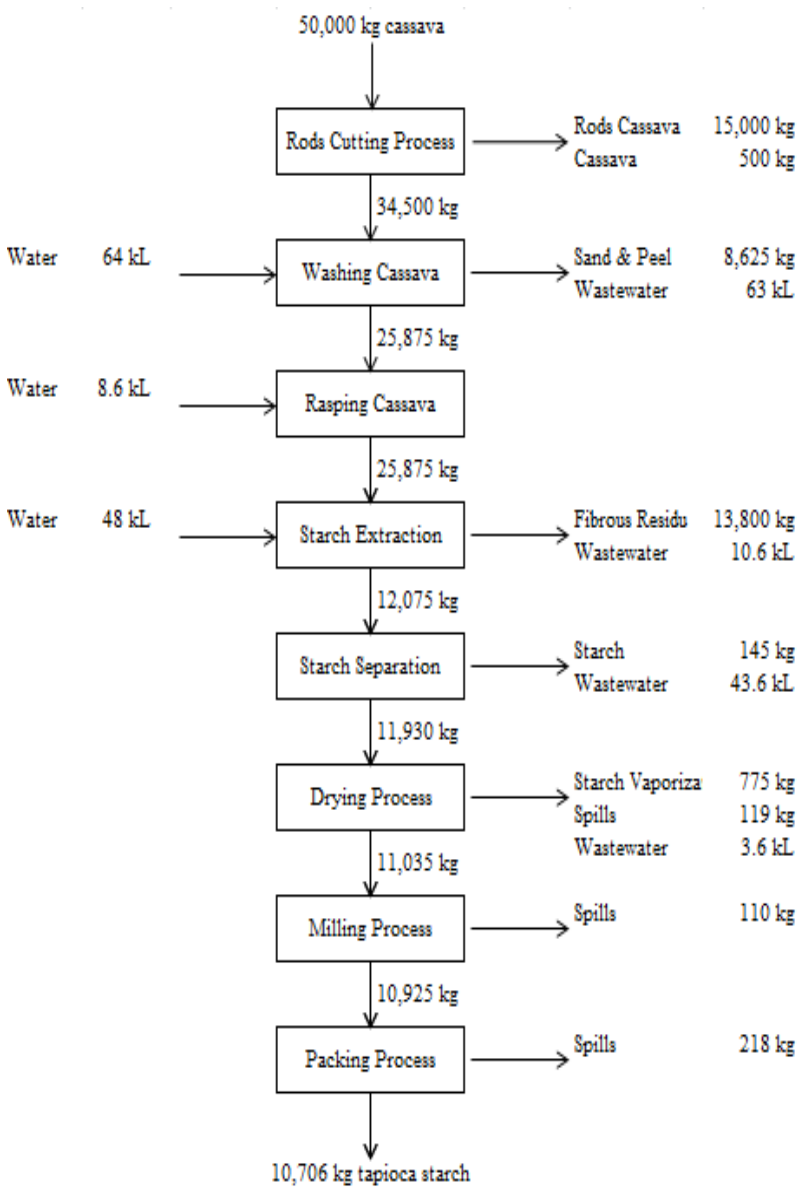

Fig. 1. Flowsheet diagram of tapioca starch production process.

Cassava roots are firstly delivered to a cutting rods process. This process held to remove stick that attached on the roots during harvesting, because the rods would affecting in the grinding process of cassava. This process is realized manually with special knife. After cutting, cassava are sent to washing process to sand removal and peeling process. In the end of peeling process, cassava roots sprayed again with clean water to ensure cassava roots was clean and ready for the rasping process. The rasping process aims to minimize size of cassava so that starch content can be extracted. Pulp cassava the results of rasping process then mixed with water to facilitate the process and then pumped to extraction process.

Extraction process has purpose to separate starch slurry and fibrous residue. During extraction process, water sprayed constantly from above to take starch from pulp. Fibrous residue (cellulose) will restrained above filter to be passed to shelter fiber and water contains tapioca slurry will pass through a filter and pumping into deposition tank to separate starch from others substances. Deposition process aims to separate pure tapioca starch by the other part such as water or contaminant substances. Deposition process lasted for approximately 4 hours, and resulted starch cake with 
water content about $40 \%$. Water and others contaminant substances are dispose to environment without any treatment.

Drying process have objective to reduce water content of tapioca cake to achieve tapioca starch with water content less than $12 \%$. Water content above $15 \%$ can cause tapioca starch be moist and quickly broken. Drying process are undertaken by conventional way by using sunlight because of costumer requirement. Drying process take time approximately 4-6 hours depend on weather and thickness of tapioca layer in drying floor. The result of drying process are coarse tapioca starch. Coarse tapioca starch then forwarded to milling process in order to size reduction and finally going to packaging process.

\subsection{Non Product Output (NPO)}

Non product output (NPO) is raw materials, supporting material, water and energy that used for production process but not contained in final product. By that definition, then waste and loss of production is part of NPO. According to the analysis of production process and cost production calculation, shows that NPO of tapioca starch production process reached $64.19 \%$. NPO breakdown per step of production process shows in fig. 2 as below.

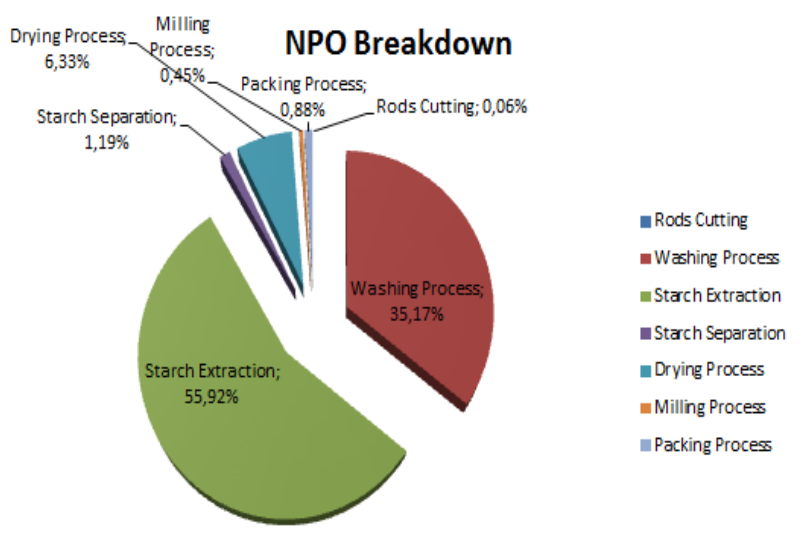

Fig. 2. NPO breakdown per step of production process

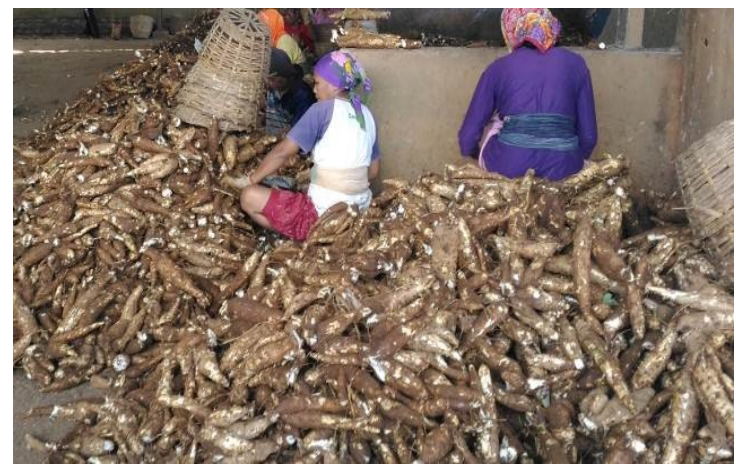

Fig. 3. Workers was doing cutting rods cassava.

\subsection{Good Housekeeping Alternatives}

Based on analysis of tapioca starch production process, several alternatives of good housekeeping were suggested and have been potentially implemented to improve production efficiency and reduce the waste generation. The good housekeeping alternatives were:

\subsubsection{Utilize pads to rods cutting process}

Currently, the process of rods cutting running with one hand held cassava and the other hand cut the rods without using pads. This certainly risk of occupational safety and potentially reduce the quantity of raw materials if workers careless and cutting the cassava come together rods. Alternative that can suggested is utilize pads while rods cutting process. The utilize of pads expected the cutting process more precisely and can minimize potential loss of cassava so the quantity of raw materials will rise.

\subsubsection{Re-use water of washing process stage 2.}

Washing process stage 2 is spraying process to cleaning cassava after peeling process. At this time, water from this process directly disposed to drain. Actually, the water from this process can be reused to washing process stage 1 . Change of this process will able to reduce water consumption in the washing process.

\subsubsection{Increasing employee's awareness at drying process.}

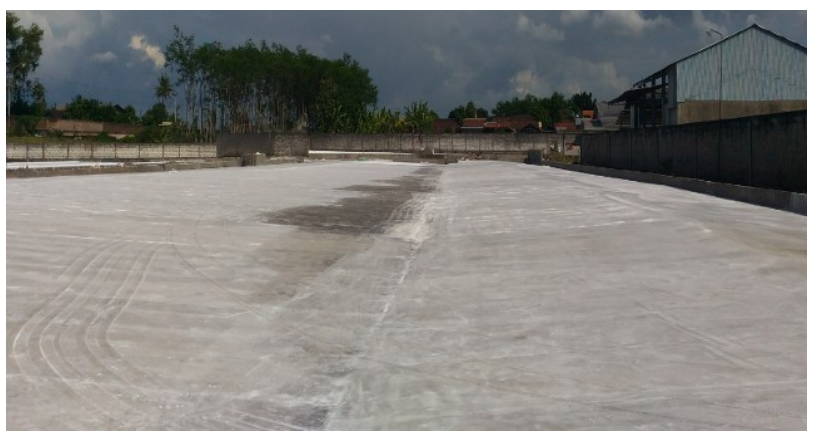

Fig. 4. Condition of the floor after drying process.

After drying process finished and tapioca starch moved to milling and packaging room, there were still founded tapioca starch left on the drying floor. This thing happened because of lack of employee's awareness about production efficiency and waste prevention. Tapioca starch that left behind should be can still continue to next process and increasing the number of final product. Good housekeeping alternative that can be suggested is to increasing employee's knowledge so can raise awareness to not leaving material that can still continue to next process. 
3.4.4 Collecting Spills of Tapioca Starch at Milling and Packaging process.

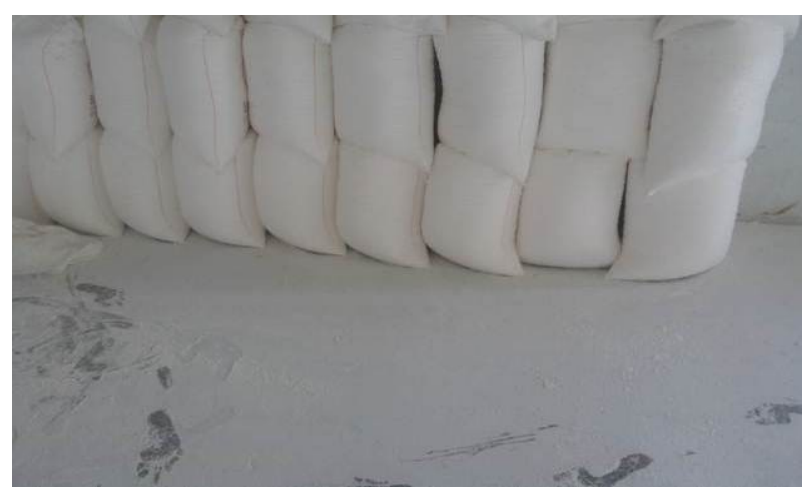

Fig. 4. Floor condition of milling and packaging room.

At milling and packaging process, spills of tapioca starch happened because of size of starch is small so easy to down. In addition, spills of tapioca starch also happens when packing process that still running manually with put the first starch on the flour before moved to sack. Good housekeeping opportunities can be applied is recollecting spills of tapioca starch using broom. Actually, broom starch has been provided, but it was rarely used by workers to collect the spills. By giving knowledge and counseling to workers that the spills of tapioca starch has actually product that can be sold but they have wasted is expected to reduce amount od spills and increase quantity of final product.

\section{Conclusions}

Tapioca starch manufacture is important in Pati regency, but often causes environmental problems because of their inefficient process and by-product generated. One of approaches that can be implemented to prevent the problems is good housekeeping. Based on analysis, alternatives good housekeeping opportunities that can be suggested such as, utilize pads on rods cutting process, increasing employee's awareness at drying process, collecting spills of tapioca starch at milling and packaging process.

\section{References}

1. S. Suroso, Department of Research and Development Kabupaten Pati (2016) (Unpublished).

2. H.T. Prayitno, Thesis Master of Environmental Science School of Postgraduate Studies Diponegoro University (2009)

3. O. Chavalparit, M. Ongwandee, J. Clepro 17, 105110 (2009).

4. United Nation Industrial Development Organization (UNIDO), Manual on the Development of Cleaner Production Policies - Approaches and Instruments, UNIDO CP Programme (2002)

5. R. Rahim, A.A.A. Raman, J. Clepro 101, 215-221 (2015).

6. Sustainable Bussiness Associates (SBA), P3U Working Paper No. 9e (1998).

7. F. J. Saez-Martinez, C. Diaz-Garcia, A. GonzalezMoreno. J. Sustainability 8, 898 (2016).

8. N. Khuriyati, W. Wagiman, D. Kumalasari, Journal of Agriculture and Agricultural Scienci Procedia 3, 102-107 (2015).

9. D. Amienyo, C. Camilleri, A. Azapagic, J. Clepro 72, 110-119 (2014).

10. H. Schollenberger, M. Treitz, J. Geldermann, J. Clepro 16, 1856-1864 (2008). 